\begin{tabular}{cc} 
Sharif University of Technology \\
Scientia Iranica \\
SCIENTIA & Transactions F: Nanotechnology \\
I RAN I CA & http://scientiairanica.sharif.edu \\
\hline
\end{tabular}

\title{
Analysis of non-Newtonian fluid with phase flow model
}

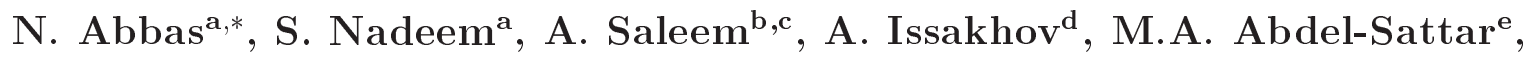 \\ and Sh. Aly \\ a. Department of Mathematics, Quaid-I-Azam University 45320, Islamabad 44000, Pakistan. \\ b. Mathematics and Its Applications in Life Sciences Research Group, Ton Duc Thang University, Ho Chi Minh City, Vietnam. \\ c. Faculty of Mathematics and Statistics, Ton Duc Thang University, Ho Chi Minh City, Vietnam. \\ d. Al-Farabi Kazakh National University, Faculty of Mechanics and Mathematics, av. al-Farabi 71, Almaty, Kazakhstan. \\ e. Department of Mathematics, College of Sciences, King Khalid University, Abha 61413, Saudi Arabia. \\ f. Department of Mathematics, Faculty of Science, Al-Azhar University, Assiut, Egypt.
}

Received 4 May 2019; received in revised form 30 September 2020; accepted 31 May 2021

\section{KEYWORDS}

Hybrid nanofluid; Second-grade fluid; Thermal slip; Numerically technique.

\begin{abstract}
In this study, we investigated a non-Newtonian fluid stagnation point on a stretching surface with slip conditions using a phase flow model. $\mathrm{Cu}$ and $\mathrm{Al}_{2} \mathrm{O}_{3}$ nanoparticles were utilized, together with the base fluid $\mathrm{H}_{2} \mathrm{O}$. The mathematical model has been built using flow assumptions and is theoretically acceptable. The momentum and energy equations are approximated using boundary layer approximations to create partial differential equations. The partial equations that are turned into ordinary differential equations are subjected to the appropriate similarity transformations. The bvp4c method is used to solve these equations numerically. Graphs and tables depict the effect of the physical parameters involved. Our findings are in good agreement with previous literature. Hybrid nanofluid achieves smaller values than nanofluid for the parameters $F^{\prime \prime}(0)$ and $-\theta^{\prime}(0)$. Furthermore, for large values of the dimensionless parameter $(\mathrm{N}), F^{\prime \prime}(0)$ and $\theta^{\prime}(0)$ grow, where as $F^{\prime}(\xi)$ and $(\theta(\xi))$ increase for large values of $\phi_{2}$.
\end{abstract}

(C) 2021 Sharif University of Technology. All rights reserved.

\section{Introduction}

Theoretical studies of non-Newtonian fluids have grown in relevance as a result of their numerous applications in science and technology. Because of the complexity of non-Newtonian fluids, no single fluid model has been suggested or explored in the literature that covers all characteristics of non-Newtonian fluid models. Due to the complexity of these models, exact solutions are nearly impossible in general. As a result, the researchers have developed their unique exact or an-

*. Corresponding author. Tel.: +92 3027122714 E-mail address: nabbas@math.qau.edu.pk (N. Abbas).

doi: $10.24200 /$ sci. 2021.53475 .3258 alytical solutions as well as numerical solutions. Early on, Rivlin and Eriksen [1] presented a second-grade fluid model. The simplest non-Newtonian fluid model exhibits many properties of the differential type fluids. Labropulu [2] studied exact solutions of the secondgrade fluid using the inverse approach. Yürüsoy et al. [3] examined the creeping flow of the second-grade fluid using the Lie group analysis. Shkoller [4] studied Euler's two-dimensional Lagrangian flow and secondgrade fluid flow. He investigated a simple proof of global existence. The second-grade fluid flow in the absence of body forces and thermal transfer was studied by Labropulu [5]. Nadeem et al. [6] investigated the series solution of the second-grade fluid flow over a shrinking sheet in the stagnation area. Mehmood et al. [7] investigated the flow of second-grade micropolar 
fluids over a stretching surface with a heat transfer. They also investigated the effects of non-orthogonal stagnation point flow. The combined effects of thermal conductivity and variable viscosity of second-grade fluids on stretching the surface were investigated by Akinbobola and Okoya [8]. The linear temperature function is inversely proportional to viscosity and directly proportional to thermal conductivity in their research. Majeed et al. [9] studied the effects of secondgrade fluid flow on the stretched cylinder with Dufour and Soret numerical impacts. They also examined the impact of thermal radiation from various angles. The effects of Dufour and Soret on temperature are observed to be directly rising. Heat transfer and secondgrade fluid of axisymmetric stretching sheets have been studied by Khan et al. [10]. Many researchers have investigated the second-grade fluid flow from various physical perspectives (see [11-18]).

The researchers were drawn to stretching analysis because of its numerous applications in engineering domains such as cooling of microelectronics, wire drawing, fast spray, polymer extrusion, glass blowing, and quenching in metal foundries. Crane [19] studied the boundary layer flow on a stretching surface theoretically earlier in the day. The flow behavior of peristaltic on stretching the surface was investigated by Mekheimer et al. [20-21]. Malvandi et al. [22] studied the effect of nanofluid on a shrinking/stretching surface near the stagnation point. Many researchers have studied stretching surfaces using a variety of assumptions [23-28].

Nanofluid is a fluid that contains nanoparticles as well as a base fluid. Choi [29] coined the term "nanofluid." He introduced the nanofluid model, claiming that nanofluids could transmit heat better than basic fluids. The numerical and theoretical analyses are satisfied by this model. Following this, several researchers worked on heat transfer enhancement due to numerous applications in engineering, industrial, and other domains. Mahian et al. [30] have studied the use of nanofluids to capture solar energy. Turkyilmazoglu [31] studied heat transfer of nanofluid on revolving disk. To investigate the flow of nanofluid, he used the SCCCM on the boundary layer flow. Abba et al. [32] studied the flow of a micropolar nanofluid in a circular cylinder. Khan et al. [33] examined the Maxwell nanofluid stagnation point flow. A number of researchers have investigated the nanofluid model using various assumptions, as shown in [33-40].

In the face of an energy shortage, researchers have focused their efforts statistically, analytically, and experimentally to attain higher heat transfer rates than decay methods. The heat transfer and coolant are the most frequently used in real life. The term "hybrid nanofluid" was used to describe a form of fluid that contains two different nanoparticles with a base fluid. This is a more comprehensive version of nanofluid. These fluids are beneficial in the fields of industry, science, and engineering. When two nanosized particles are mixed with a base fluid, the fluid thermal conductivity is increased above that of nanofluid and simple fluid. For the first time, Momin [41] acquired his conclusions through an experimental study of a hybrid nanofluid with mixed convection. Suresh et al. [42] studied a hybrid nanofluid and provided analytical results. The work of Suresh et al. [42] has been extended by a number of researchers to estimate heat transfer rates under various assumptions. Nadeem and Abbas [43] have studied the stagnation flows of hybrid nanofluid in a circular cylinder. Taking into account a number of important physical properties as observed in [44-50], a number of researchers have recently studied the hybrid nanofluid.

The purpose of this study is to investigate the effects of using a phase flow model with a secondgrade fluid flow over a stretching surface. In this study, slip effects and hybrid nanofluids are taken into account. This system has been transformed into an ordinary differential equations system. The altered system is solved using the bvp4c Method, which is a numerical scheme. Figures and tables illustrate the effects of involving governing parameters. No one had ever investigated hybrid nanofluid with second-grade before.

\section{Mathematical formulations}

We investigated second-grade hybrid nanofluid stagnation point flow with slip conditions across a stretching surface. The velocity components in the $X$ - and $Y$ axes, respectively, are $V$ and $W$. Stagnation point flow is defined as $V=a X$ and $W=a Y$, with $a$ serving as a stretching parameter (see [48,51-55]).

$$
\begin{aligned}
& \frac{\partial V}{\partial X}+ \frac{\partial W}{\partial Y}=0 \\
& V \frac{\partial V}{\partial X}+W \frac{\partial V}{\partial Y}=-\frac{1}{\rho_{h n_{f}}} \frac{\partial P}{\partial X}+\frac{\mu_{h n_{f}}}{\rho_{h n_{f}}} \frac{\partial^{2} V}{\partial Y^{2}} \\
&+\frac{\alpha}{\rho_{h n_{f}}}\left(V \frac{\partial^{3} V}{\partial X \partial Y^{2}}+\frac{\partial V}{\partial X} \frac{\partial^{2} V}{\partial Y^{2}}\right. \\
&\left.+\frac{\partial V}{\partial X} \frac{\partial^{2} V}{\partial Y \partial X}+W \frac{\partial^{3} V}{\partial Y^{3}}\right) \\
& V \frac{\partial T}{\partial X}+W \frac{\partial T}{\partial Y}=\alpha_{h n_{f}} \frac{\partial^{2} T}{\partial Y^{2}} .
\end{aligned}
$$

The continuity, momentum, and energy equations for the hybrid nanofluid are shown in Eqs. (1)-(3). It is worth noting that for phase flow models, experimental data for both nanofluid and hybrid nanofluid are often 
Table 1. Physical properties nanofluid and hybrid nanofluid of thermodynamics.

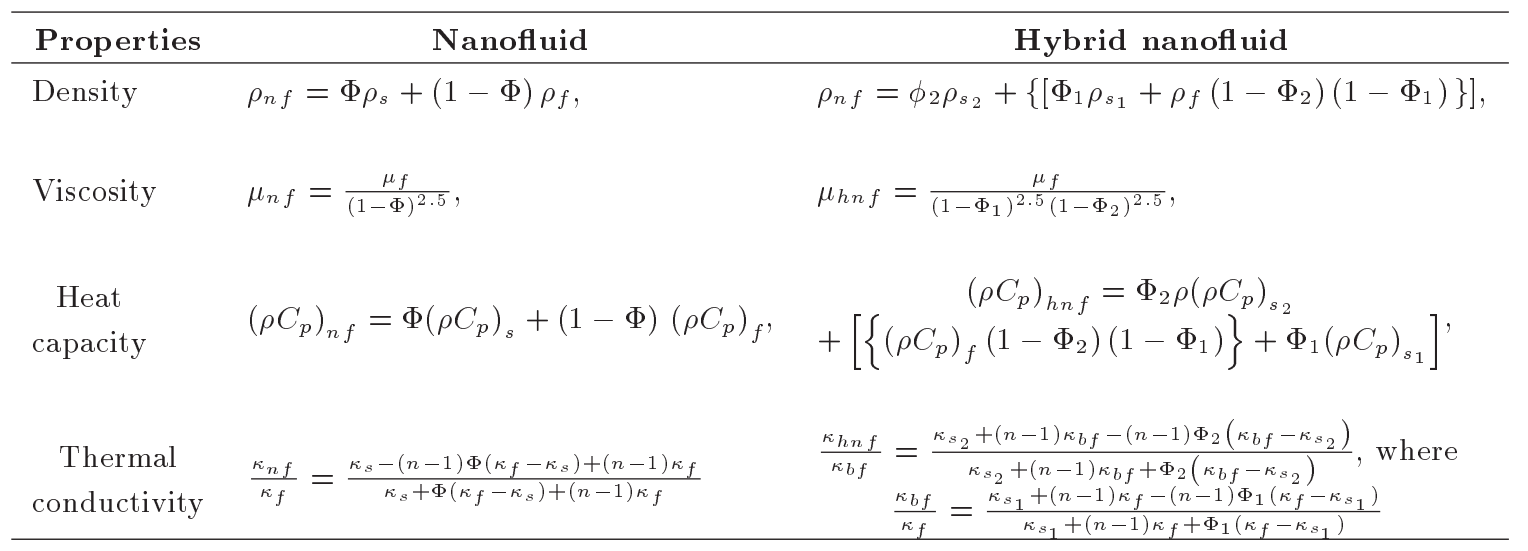

provided only for a Newtonian fluid. We make a tiny change, in this case, replacing $\frac{\alpha}{\rho_{h n_{f}}}$ with $\left(\frac{\mu_{h n_{f}}}{\rho_{h n_{f}}}\right)\left(\frac{N-1}{N}\right)$ in which $N \neq 0$. The viscoelastic fluid model was produced for $N$ values ranging from 0 to 1 . For $N>1$, the results of a second-grade fluid model were obtained. We can get a viscous fluid model if $N=1$ (Newtonian fluid model). The order of the entire term is assumed to be $o\left(\delta^{2}\right)$. Now, we assume from a mathematical standpoint that:

$$
\left(\frac{\mu_{h n_{f}}}{\rho_{h n_{f}}}\right)\left(\frac{N-1}{N}\right)=\frac{\alpha}{\rho_{h n_{f}}} .
$$

The order of approximation such as $o(V)=o(1)=$ $o(X)$ and $o(Y)=o(\delta)=o(W)$ is evident. From a mathematical standpoint, we now incorporate $\left(\frac{\mu_{h n_{f}}}{\rho_{h n_{f}}}\right)\left(\frac{N-1}{N}\right)=\frac{\alpha}{\rho_{h n_{f}}}=o\left(\delta^{2}\right)$ in our assumptions. This phenomenon could exist in the form of:

$$
\left(\frac{\mu_{h n_{f}}}{\rho_{h n_{f}}}\right)\left(\frac{N-1}{N}\right)=\frac{\alpha}{\rho_{h n_{f}}}=o\left(\delta^{2}\right) .
$$

The physical properties are defined in Tables 1 and 2. $\alpha_{h n_{f}}, N, \mu_{h n_{f}}, \rho_{h n_{f}}$, and $P$ are the thermal diffusivity hybrid nanofluid, dimensionless parameter, viscosity hybrid nanofluid, density of hybrid nanofluid and pressure, respectively. The boundary conditions can be expressed as follows:

$$
\begin{aligned}
& W=0, \quad V=0, \\
& V=\omega_{1}\left[\frac{\partial V}{\partial Y}+\left(\frac{\mu_{h n_{f}}}{\rho_{h n_{f}}}\right)\left(\frac{N-1}{N}\right)\right. \\
& \left.\quad\left\{\frac{\partial V}{\partial X} \frac{\partial V}{\partial Y}+W \frac{\partial^{2} V}{\partial Y^{2}}+V \frac{\partial^{2} V}{\partial Y \partial X}\right\}\right], \\
& -k_{h n_{f}} \frac{\partial T}{\partial Y}=h_{w}\left(T_{w}-T\right) \quad \text { as : } \\
& Y \rightarrow 0, \quad T=T_{\infty}, \quad V=a X, \quad W=0, \quad Y \rightarrow \infty,
\end{aligned}
$$

Table 2. Thermo-physical properties.

\begin{tabular}{cccc}
\hline $\begin{array}{c}\text { Thermo-physical } \\
\text { properties }\end{array}$ & $\begin{array}{c}\text { Base fluid } \\
\left(\mathbf{H}_{\mathbf{2}} \mathbf{O}\right)\end{array}$ & $\mathbf{A l}_{\mathbf{2}} \mathbf{O}_{\mathbf{3}}$ & $\mathbf{C u}$ \\
\hline$\rho\left(\mathrm{kg} / \mathrm{m}^{3}\right)$ & 997.1 & 3970 & 8933 \\
$k(\mathrm{~W} / \mathrm{mK})$ & 0.613 & 40 & 400 \\
$C_{p}(\mathrm{j} / \mathrm{kg}) \mathrm{K}$ & 4179 & 765 & 385 \\
\hline
\end{tabular}

where $\omega_{1}, h_{w}, T_{w}$, and $T_{\infty}$ are velocity slip parameter, temperature slip parameter, wall temperature, dimensionless and the ambient temperature, respectively. The following is the non-dimensional form of the appropriate similarity transformation:

$$
\begin{aligned}
& \zeta=\left(a / \nu_{f}\right)^{1 / 2} Y, \quad V=a X F^{\prime}(\zeta), \\
& T=\left(T_{0}-T_{w}\right) \theta(\zeta)+T_{\infty}, \quad W=-\left(a \nu_{f}\right)^{1 / 2} F(\zeta) .
\end{aligned}
$$

When the preceding equations are applied, Eq. (1) is satisfied in the same way, and Eqs. (2) and (3) are reduced to the following form:

$$
\begin{aligned}
\left(\frac{\mu_{h n_{f}}}{\rho_{h n_{f}}}\right) F^{\prime \prime \prime}(\zeta) & +\left(\frac{\mu_{h n_{f}}}{\rho_{h n_{f}}}\right)\left(\frac{N-1}{N}\right)\left(2 F^{\prime \prime \prime}(\zeta) F^{\prime}(\zeta)\right. \\
& \left.+F^{\prime \prime}(\zeta) F^{\prime \prime}(\zeta)-F(\zeta) F^{\prime \prime \prime}(\zeta)\right)+1 \\
& +F^{\prime}(\zeta) F^{\prime \prime}(\zeta)-F^{\prime}(\zeta) F^{\prime}(\zeta)=0 \\
\alpha_{h n_{f}} \theta^{\prime \prime}(\zeta)+ & F(\zeta) \theta^{\prime}(\zeta)=0
\end{aligned}
$$

Using Eqs. (4) and (5), the dimensionless version of the boundary conditions is shown below:

$$
\begin{aligned}
& F^{\prime}(\zeta)=\lambda F^{\prime \prime}(\zeta)\left(1+3\left(\frac{\mu_{h n_{f}}}{\rho_{h n_{f}}}\right)\left(\frac{N-1}{N}\right) F^{\prime}(\zeta)\right), \\
& F(\zeta)=0, \quad \theta(\zeta)-1=\left(\frac{k_{h n_{f}}}{k_{f}}\right) \gamma \theta^{\prime}(\zeta), \quad \text { as } \quad \zeta \rightarrow 0 \\
& \theta(\zeta)=0, \quad F^{\prime}(\zeta)=1, \quad \zeta \rightarrow \infty .
\end{aligned}
$$


Thermal slip, velocity slip, and non-dimensional parameters $\gamma, \lambda$ and $\xi$ are examples of non-dimensional parameters. $N u_{X}$ is defined as:

$$
N u_{X}=-\left(\frac{k_{h n_{f}}}{k_{f}}\right)\left(X /\left(T_{w}-T_{\infty}\right)\right)\left(\frac{\partial T}{\partial Y}\right)_{Y=0},
$$

and the skin friction coefficient can be obtained as follows:

$$
\begin{aligned}
C_{f}= & {\left[\frac{\partial V}{\partial Y}+\left(\frac{\mu_{h n_{f}}}{\rho_{h n_{f}}}\right)\left(\frac{N-1}{N}\right)\left\{\frac{\partial V}{\partial X} \frac{\partial V}{\partial Y}+W \frac{\partial^{2} V}{\partial Y^{2}}\right.\right.} \\
& \left.\left.+V \frac{\partial^{2} V}{\partial Y \partial X}\right\}\right]_{Y=0} \cdot
\end{aligned}
$$

$R e_{X}=\left(a X^{2}\right) / v_{f}$ is the local Reynolds number.

\section{Solution procedure}

We used a second-grade hybrid nanofluid over a stretched surface in the stagnation point region for this study. Flow assumptions were used to build the mathematical model. The boundary layer approximations on the Navier Stokes equations are used to create partial differential equations. The partial equations that are turned into ordinary differential equations are subjected to the appropriate similarity transformations. The numerical scheme used to solve these equations is the bvp $4 \mathrm{c}$ method. We must figure out how to solve the above-mentioned system. We start with three assumptions such as:

- If $K=\frac{\mu_{h n f}}{\rho_{h n f}}\left(\frac{N-1}{N}\right)$ and $\Phi_{1}=0=\Phi_{2}$ while $N \notin$ $[0,1]$ then this system becomes a second-grade fluid model;

- If $K=\frac{\mu_{h n f}}{\rho_{h n f}}\left(\frac{N-1}{N}\right)$ and $\Phi_{1}=0=\Phi_{2}$ while $N \in[0,1]$ then this system becomes a viscoelastic fluid model.

For large values of the velocity slip parameter, the velocity profile gains boundary layer thickness, as shown in Figure 1. When thermal slip rises, the temperature profile curve declines, as shown in Figure 1. Table 3 shows how our findings could be compared to those of Ariel [51]. As can be seen, our findings are in good agreement with Ariel [51]. This model becomes a Newtonian fluids model if $N=1$ and the rest of the physical parameters are fixed. The present results are compared to the previous literature. Table 4 shows the comparison between our results corresponding to $F^{\prime \prime}(0)$ for different values of $\lambda$ with those provided by Bachok et al. [53] and Wang [52]. When $\Phi_{1}=\Phi_{2}=0$, it is shown to be in good agreement with Bachok et al. [53] and Wang [52]. Table 5 shows the effect of velocity slip $\lambda$ and nanoparticle concentration $\Phi_{2}$ on the $\frac{N u_{X}}{\sqrt{R e_{X}}}$ and $\frac{C_{f}}{\sqrt{R e_{X}}}$. Table 5 shows that our findings

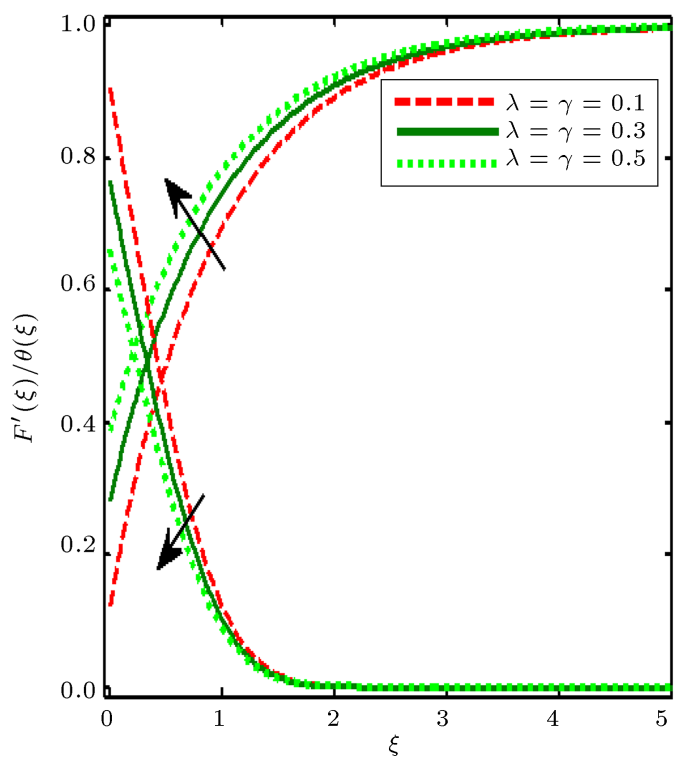

Figure 1. Influence of $\mathrm{Cu}-\mathrm{Al}_{2} \mathrm{O}_{3} / \mathrm{H}_{2} \mathrm{O}$ and $\mathrm{Cu} / \mathrm{H}_{2} \mathrm{O}$ on $\theta(\xi)$ and $F^{\prime}(\xi)$.

Table 3. Numerical results of [48] compared with the present results.

\begin{tabular}{cccc}
\hline$\frac{(N-1)}{N}$ & $\begin{array}{c}\text { Present } \\
\text { solution }\end{array}$ & $\begin{array}{c}\text { Approximate } \\
\text { solution [48] }\end{array}$ & $\begin{array}{c}\text { Exact } \\
\text { solution }[48]\end{array}$ \\
\hline- & $\boldsymbol{F}^{\prime \prime}(\mathbf{0})$ & $\boldsymbol{F}^{\prime \prime}(\mathbf{0})$ & $\boldsymbol{F}^{\prime \prime}(\mathbf{0})$ \\
\hline 0.0 & 1.232479 & 1.232588 & 1.224745 \\
0.05 & 1.169785 & 1.179830 & 1.185498 \\
0.1 & 1.121512 & 1.134114 & 1.149241 \\
0.2 & 1.078543 & 1.058131 & 1.084652 \\
0.3 & 1.019854 & 0.996844 & 1.028992 \\
0.4 & 0.965843 & 0.945869 & 0.980581 \\
0.5 & 0.923564 & 0.902500 & 0.938083 \\
1.0 & 0.778532 & 0.752766 & 0.784465 \\
2 & 0.609856 & 0.596769 & 0.618347 \\
3 & 0.517703 & 0.510703 & 0.526235 \\
4 & 0.460396 & 0.453968 & 0.465812 \\
5 & 0.413285 & 0.412885 & 0.422308 \\
6 & 0.379865 & 0.381336 & 0.389071 \\
7 & 0.353241 & 0.356110 & 0.362613 \\
8 & 0.340521 & 0.335335 & 0.340905 \\
10 & 0.306571 & 0.302828 & 0.307093 \\
20 & 0.221324 & 0.218554 & 0.220316 \\
50 & 0.141241 & 0.140077 & 0.140579 \\
100 & 0.099854 & 0.099515 & 0.099701 \\
\hline & & &
\end{tabular}

are in good accord with those of Yacob et al. [55] and Bachok et al. [53]. Table 6 shows the effects of $\lambda$ on the $F^{\prime \prime}(0)$. It is observed that there is good agreement between our findings and those of Bachok et al. [53] and 
Table 4. Numerical results of [52] and [53] compared with the present results with $\Phi_{1}=\Phi_{2}=0$.

\begin{tabular}{cccc}
\hline $\boldsymbol{\lambda}$ & $\begin{array}{c}\text { Present } \\
\text { results }\end{array}$ & $\begin{array}{c}\text { Bachok } \\
\text { et al. }[\mathbf{5 3}]\end{array}$ & $\begin{array}{c}\text { Wang } \\
{[\mathbf{5 2}]}\end{array}$ \\
\hline- & $\boldsymbol{F}^{\prime \prime}(\mathbf{0})$ & $\boldsymbol{F}^{\prime \prime}(\mathbf{0})$ & $\boldsymbol{F}^{\prime \prime}(\mathbf{0})$ \\
\hline 0 & 1.225684 & 1.232588 & 1.232588 \\
0.5 & 0.712358 & 0.713295 & 0.71330 \\
1.0 & 0 & 0 & 0 \\
2.0 & 1.225684 & -1.887307 & -1.88731 \\
\hline
\end{tabular}

Malvandi et al. [54]. Let us analyze phase flow with a second-grade fluid under the mathematical assumption of $O\left(\delta^{2}\right)=\left(\frac{\mu_{h n f}}{\rho_{h n f}}\right)\left(\frac{N-1}{N}\right)=\left(\frac{\alpha}{\rho_{h n f}}\right)$. Our hypothesis is determined to be in good accord with the existing literature, and the order of approximation is also met.

\section{Results and discussions}

The purpose of this analysis is to demonstrate the impact of physical parameters on the temperature and velocity profiles. Nanoparticle concentration of aluminium oxide $\left(\Phi_{1}\right)$, nanoparticle concentration of copper $\left(\Phi_{2}\right)$, velocity slip parameter $(\lambda)$, dimensionless parameter $(N)$ and thermal slip parameter $(\gamma)$ are the physical parameters involved. In the whole investigation, the nanoparticle concentration of aluminum oxide $\left(\Phi_{1}=0.1\right)$ is assumed to be constant. The range of the physical parameters is considered as $0.005 \leq \Phi_{2} \leq$ 0.09 , and $0.0 \leq \gamma \leq 0.5$, and $0.0 \leq \lambda \leq 0.5$, and the dimensionless parameter is considered to be $N \notin$ $[0,1]$. The effects of physical parameters are shown through figures and tables. The comparative analysis of $\mathrm{Cu}-\mathrm{Al}_{2} \mathrm{O}_{3} / \mathrm{H}_{2} \mathrm{O}$ and $\mathrm{Cu} / \mathrm{H}_{2} \mathrm{O}$ on $F^{\prime}(\xi)$ and $\theta(\xi)$ are shown in Figures 2 and 3 . It should be noted that $F^{\prime}(\xi)$ improves with rising in the $\Phi_{2} \cdot \mathrm{Cu}-\mathrm{Al}_{2} \mathrm{O}_{3} / \mathrm{H}_{2} \mathrm{O}$ achieves a larger moment boundary layer thickness than $\mathrm{Cu} / \mathrm{H}_{2} \mathrm{O}$. Figure 3 shows the impacts of $\Phi_{2}$ on $\theta(\xi)$. It is worth noting that as the value of $\Phi_{2}$ rises, so does the size of $\theta(\xi)$. Cu- $\mathrm{Al}_{2} \mathrm{O}_{3} / \mathrm{H}_{2} \mathrm{O}$ has a greater thermal boundary layer thickness gain than $\mathrm{Cu} / \mathrm{H}_{2} \mathrm{O}$. Figures 4 and 5 show the effects of $\Phi_{2}$ on $\theta(\xi)$ and $F^{\prime}(\xi)$. It is shown that $\theta(\xi)$ and $F^{\prime}(\xi)$ increase as $\Phi_{2}$ increases, indicating a high resistance to fluid velocity.
Table 6. Comparative results of [53] and [54] with the present results with $\Phi_{2}=0.1$ and $\Phi_{1}=0$.

\begin{tabular}{cccc}
\hline $\boldsymbol{\lambda}$ & $\begin{array}{c}\text { Bachok } \\
\text { et al. [53] }\end{array}$ & $\begin{array}{c}\text { Malvandi } \\
\text { et al. [54] }\end{array}$ & $\begin{array}{c}\text { Present } \\
\text { results }\end{array}$ \\
\hline- & $\boldsymbol{F}^{\prime \prime}(\mathbf{0})$ & $\boldsymbol{F}^{\prime \prime}(\mathbf{0})$ & $\boldsymbol{F}^{\prime \prime}(\mathbf{0})$ \\
\hline 0.0 & 1.447977 & 1.447977471 & 1.3578 \\
0.5 & 0.83794 & 0.837940401 & 0.8238 \\
1.0 & 0.0 & 0.0 & 0.0 \\
1.5 & - & -1.026658507 & -1.0252 \\
2.0 & -2.217106 & -2.217105947 & -2.1987 \\
\hline
\end{tabular}

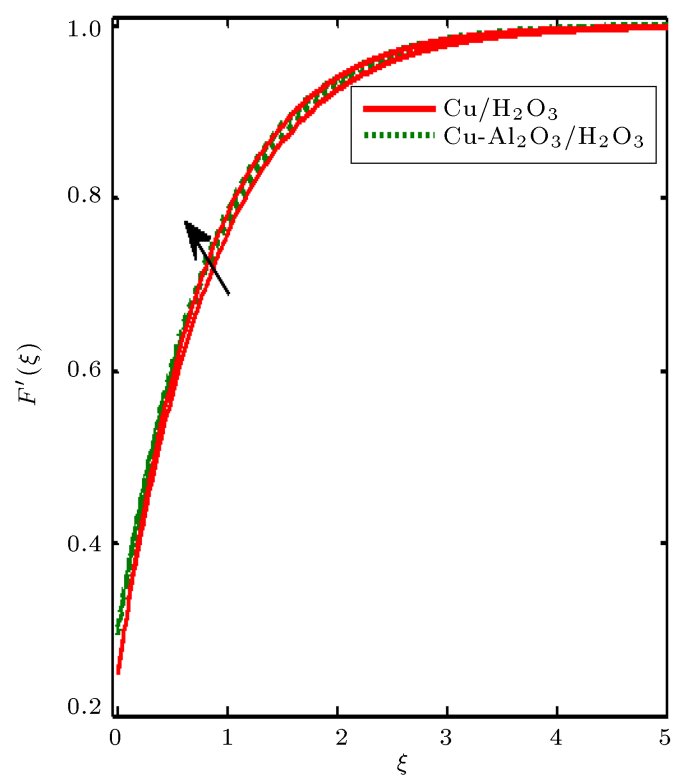

Figure 2. Effects of $\mathrm{Cu} / \mathrm{H}_{2} \mathrm{O}$ and $\mathrm{Cu}-\mathrm{Al}_{2} \mathrm{O}_{3} / \mathrm{H}_{2} \mathrm{O}$ on $\theta(\xi)$.

Figure (6) shows the impact of thermal slip on $\theta(\xi)$ and velocity slip on the velocity profile. It is observed that $F^{\prime}(\xi)$ increases as the velocity slip parameter increases but $\theta(\xi)$ exhibits a drop in the curve as the thermal slip parameter increases. Figure (6) shows the effects of dimensionless parameter on $\theta(\xi)$ and $F^{\prime}(\xi)$. It is seen that $F^{\prime}(\xi)$ increases as the dimensionless parameter $(N)$ increase, and $\theta(\xi)$ decreases as the dimensionless parameter $(N)$ increases, as shown in Figure 7 . For large values of the dimensionless parameter, the thickness of the momentum boundary layer increases while

Table 5. Numerical results of [52] and [54] compared with the present results with $\Phi_{1}=0$.

\begin{tabular}{|c|c|c|c|c|c|c|c|}
\hline \multicolumn{2}{|c|}{$\mathrm{Cu} / \mathrm{H}_{2} \mathrm{O}$} & \multicolumn{2}{|c|}{ Present results } & \multicolumn{2}{|c|}{ Bachok et al. [53] } & \multicolumn{2}{|c|}{ Yacob et al. [55] } \\
\hline$\Phi_{2}$ & $\lambda$ & $\frac{C_{f}}{\sqrt{\left(R e_{X}\right)}}$ & $\frac{N u_{x}}{\sqrt{\left(R e_{X}\right)}}$ & $\frac{C_{f}}{\sqrt{\left(R e_{X}\right)}}$ & $\frac{N u_{x}}{\sqrt{\left(R e_{X}\right)}}$ & $\frac{C_{f}}{\sqrt{\left(R e_{X}\right)}}$ & $\frac{N u_{x}}{\sqrt{\left(R e_{X}\right)}}$ \\
\hline 0.1 & 0.0 & 1.7968 & 1.4043 & 1.8843 & 1.4043 & 1.8843 & 1.4043 \\
\hline 0.2 & 0.5 & 2.4589 & 1.6421 & 2.6226 & 1.6692 & 2.6226 & 1.6692 \\
\hline 0.1 & 0.0 & 1.0795 & 1.7895 & 1.0904 & 1.8724 & - & - \\
\hline 0.2 & 0.5 & 1.5004 & 2.0987 & 1.5177 & 2.1577 & - & - \\
\hline
\end{tabular}




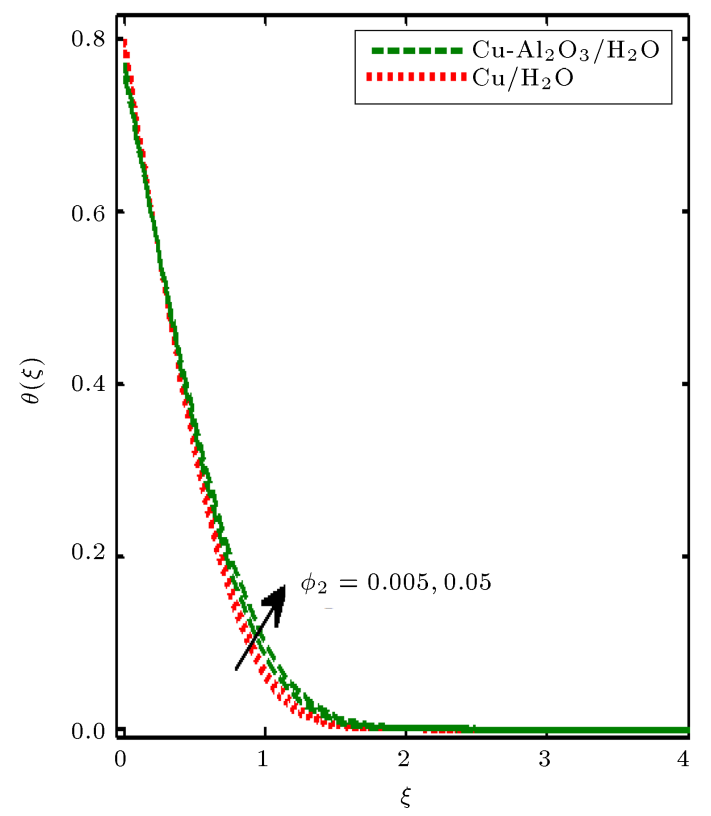

Figure 3. Effects of $\mathrm{Cu} / \mathrm{H}_{2} \mathrm{O}$ and $\mathrm{Cu}-\mathrm{Al}_{2} \mathrm{O}_{3} / \mathrm{H}_{2} \mathrm{O}$ on $\theta(\xi)$.

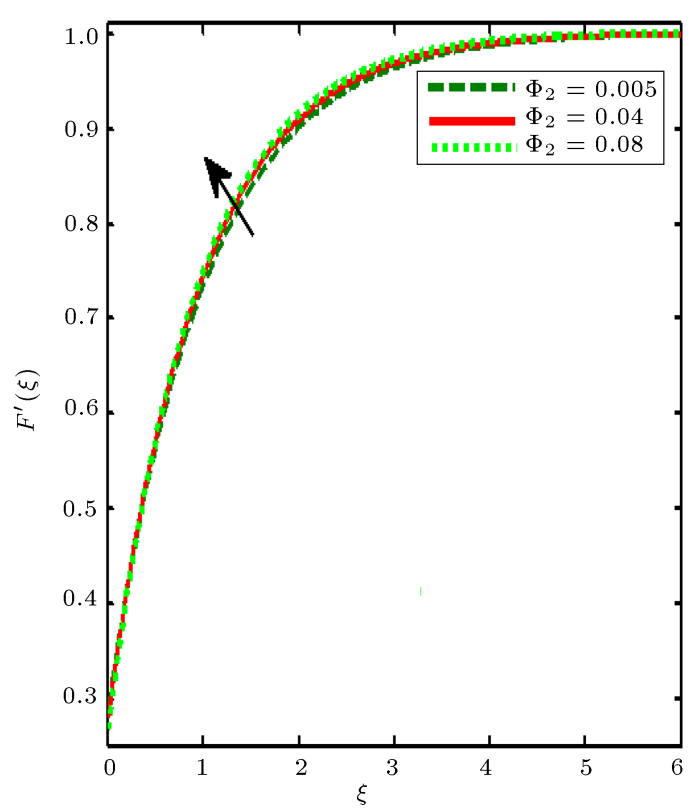

Figure 4. Effects of $\Phi_{2}$ on $F^{\prime}(\xi)$.

the thickness of the thermal boundary layer decreases. Table 7 shows the impacts of physical parameters $\Phi_{2}, \gamma$, $\lambda$, and $N$ on $\theta^{\prime}(0)$ and $F^{\prime \prime}(0)$. We also conducted a comparative investigation, which included a comparison of $\mathrm{Cu}-\mathrm{Al}_{2} \mathrm{O}_{3} / \mathrm{H}_{2} \mathrm{O}$ and $\mathrm{Cu} / \mathrm{H}_{2} \mathrm{O}$. We observed that as $F^{\prime \prime}(0)$ increases $\Phi_{2}$ increases. The values of $F^{\prime \prime}(0)$ are lower in $\mathrm{Cu}-\mathrm{Al}_{2} \mathrm{O}_{3} / \mathrm{H}_{2} \mathrm{O}$, than in $\mathrm{Cu} / \mathrm{H}_{2} \mathrm{O}$. For larger values of $\theta^{\prime}(0) \Phi_{2}$, the $\theta^{\prime}(0)$ decreases, whereas $\mathrm{Cu}-$ $\mathrm{Al}_{2} \mathrm{O}_{3} / \mathrm{H}_{2} \mathrm{O}$ gains smaller values of $\theta^{\prime}(0)$ than $\mathrm{Cu} / \mathrm{H}_{2} \mathrm{O}$. The effects of thermal slip on $\theta^{\prime}(0)$ are shown in Table 7. It can be seen that as the value of $\theta^{\prime}(0)$ is decreased, thermal sip increases. $\mathrm{Cu}-\mathrm{Al}_{2} \mathrm{O}_{3} / \mathrm{H}_{2} \mathrm{O}$ gains smaller

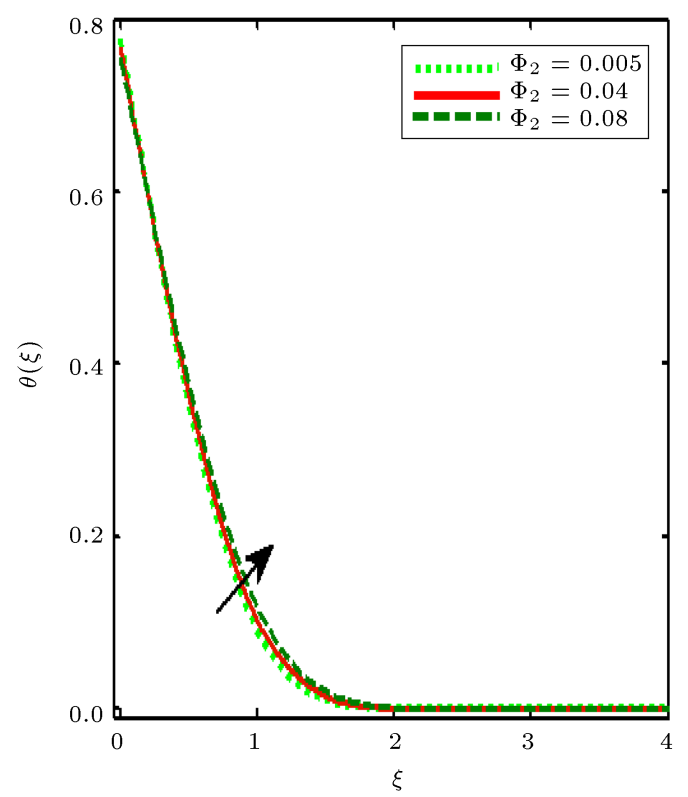

Figure 5. Effects of $\Phi_{2}$ on $\theta(\xi)$.

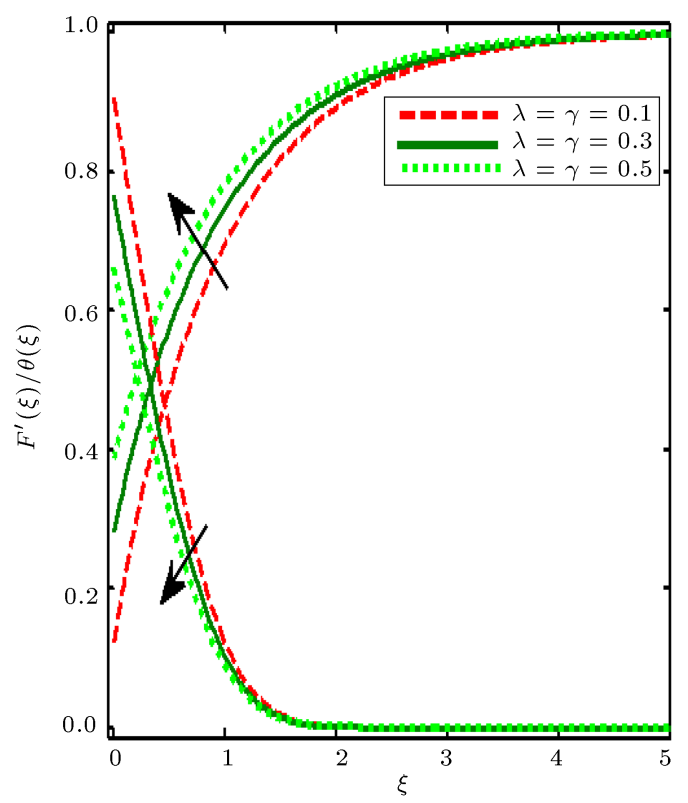

Figure 6. Effects of $N, \gamma$ and $\lambda$ on $F^{\prime}(\xi)$.

values of $\theta^{\prime}(0)$ than $\mathrm{Cu} / \mathrm{H}_{2} \mathrm{O}$. Table 7 shows the effects of velocity slip on the $F^{\prime \prime}(0)$ and $\theta^{\prime}(0)$. With a rise in $\theta^{\prime}(0)$ and a decrease in $F^{\prime \prime}(0)$ the velocity slip increases. It is observed that $\mathrm{Cu}-\mathrm{Al}_{2} \mathrm{O}_{3} / \mathrm{H}_{2} \mathrm{O}$ gains smaller values than $\mathrm{Cu} /\left(\mathrm{H}_{2} \mathrm{O}\right)$ which is surprising. With increases in $\theta^{\prime}(0)$ and $F^{\prime \prime}(0)$ the dimensionless parameter increases. It is also observed that $\mathrm{Cu}-\mathrm{Al}_{2} \mathrm{O}_{3} / \mathrm{H}_{2} \mathrm{O}$ gains smaller values than $\mathrm{Cu} / \mathrm{H}_{2} \mathrm{O}$.

\section{Final remarks}

We have studied a second-grade hybrid nanofluid stagnation point flow over a stretching surface with 
Table 7. Skin frictions and Nusselt numbers of $\mathrm{Cu}-\mathrm{Al}_{2} \mathrm{O}_{3} / \mathrm{H}_{2} \mathrm{O}$ and $\mathrm{Cu} / \mathrm{H}_{2} \mathrm{O}$.

\begin{tabular}{|c|c|c|c|c|c|c|c|}
\hline \multirow[b]{2}{*}{$\Phi_{2}$} & \multirow[b]{2}{*}{$\gamma$} & \multirow[b]{2}{*}{$\lambda$} & \multirow[b]{2}{*}{$N$} & \multicolumn{2}{|c|}{$\mathrm{Cu}-\mathrm{Al}_{2} \mathrm{O}_{3} / \mathrm{H}_{2} \mathrm{O}$} & \multicolumn{2}{|c|}{$\mathrm{Cu} / \mathrm{H}_{2} \mathrm{O}$} \\
\hline & & & & $F^{\prime \prime}(0)$ & $-\theta^{\prime}(0)$ & $F^{\prime \prime}(0)$ & $-\theta^{\prime}(0)$ \\
\hline 0.005 & 0.3 & 0.03 & 2.0 & 0.787087 & 0.925585 & 0.854221 & 1.0598 \\
\hline 0.02 & - & - & - & 0.809948 & 0.903288 & 0.885582 & 1.03756 \\
\hline 0.04 & - & - & - & 0.838365 & 0.87378 & 0.923625 & 1.00711 \\
\hline 0.06 & - & - & - & 0.86466 & 0.844716 & 0.957992 & 0.976308 \\
\hline 0.08 & - & - & - & 0.888998 & 0.816229 & 0.989151 & 0.945545 \\
\hline 0.04 & 0.1 & - & - & 0.838365 & 1.03848 & 0.923625 & 1.16947 \\
\hline- & 0.2 & - & - & 0.838365 & 0.949037 & 0.923625 & 1.08223 \\
\hline- & 0.3 & - & - & 0.838365 & 0.87378 & 0.923625 & 1.00711 \\
\hline- & 0.4 & - & - & 0.838365 & 0.809582 & 0.923625 & 0.941738 \\
\hline- & 0.3 & 0.1 & - & 1.0672 & 0.802870 & 1.13178 & 0.925748 \\
\hline- & - & 0.2 & - & 0.937379 & 0.842992 & 1.01565 & 0.970982 \\
\hline- & - & 0.3 & - & 0.838365 & 0.87378 & 0.923625 & 1.00711 \\
\hline- & - & 0.4 & - & 0.759557 & 0.898241 & 0.848211 & 1.03673 \\
\hline- & - & 0.3 & 0.0 & 0.322344 & 0.648421 & 0.348645 & 0.734637 \\
\hline- & - & - & 2.0 & 0.838365 & 0.87378 & 0.923625 & 1.00711 \\
\hline
\end{tabular}

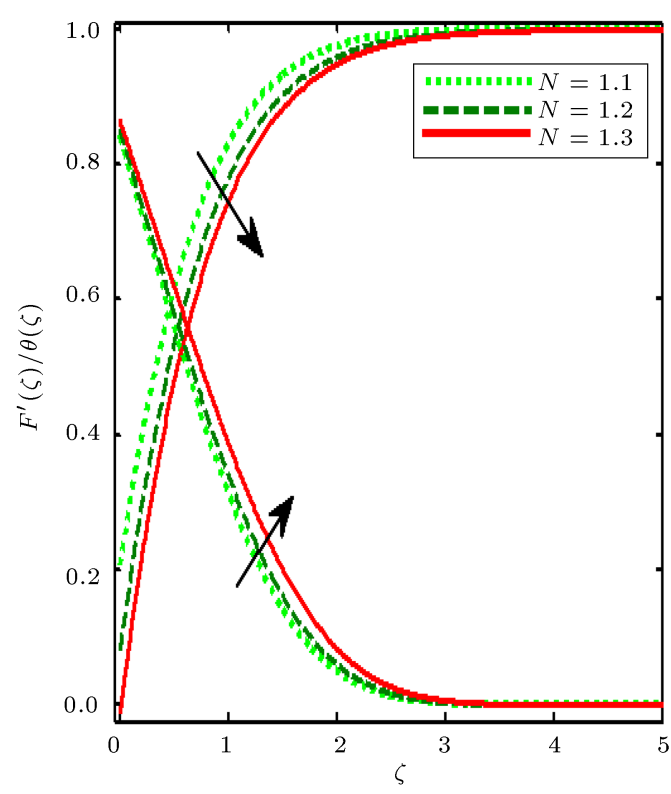

Figure 7. Effects of $N, \gamma$ and $\lambda$ on $\theta(\xi)$.

slip conditions. Tables and figures are used to show physical parameters that are involved. Surprisingly, we found some important results, as below:

- $\mathrm{Cu}-\mathrm{Al}_{2} \mathrm{O}_{3} / \mathrm{H}_{2} \mathrm{O}$ obtains lower values than $\mathrm{Cu} / \mathrm{H}_{2} \mathrm{O}$ for $F^{\prime \prime}(0)$ and $-\theta^{\prime}(0)$;

- For large values of the dimensionless parameter $(N)$, $F^{\prime \prime}(0)$ and $-\theta^{\prime}(0)$ increase in both cases;

- $F^{\prime}(\xi)$ and $\theta(\xi)$ increase for large values of $\Phi_{2}$;
- Our findings are in good agreement with the previous literature.

\section{Acknowledgment}

The authors extend their appreciation to the Deanship of Scientific Research at King Khalid University, Abha 61413, Saudi Arabia for funding this work through research groups program under grant number G.R.P$26 / 1441$.

\section{References}

1. Rivlin, R.S., and Ericksen, J.L. "Stress-deformation relations for isotropic materials", In Collected Papers of RS Rivlin, pp. 911-1013, Springer, New York, NY (1997).

2. Labropulu, F.A "Few more exact solutions of a second grade fluid via inverse method", Mechanics Research Communications, 27(6), pp. 713-720 (2000).

3. Yürüsoy, M., Pakdemirli, M., and Noyan, Ö.F. "Lie group analysis of creeping flow of a second grade fluid", International Journal of Non-Linear Mechan$i c s, 36(6)$, pp. 955-960 (2001).

4. Shkoller, S. "Smooth global Lagrangian flow for the 2D Euler and second-grade fluid equations", Applied Mathematics Letters, 14(5), pp. 539-543 (2001).

5. Labropulu, F. "D'Alembert motions for nonNewtonian second grade fluid", International Journal of Non-linear Mechanics, 38(7), pp. 1027-1036 (2003). 
6. Nadeem, S., Hussain, A., Malik, M.Y., and Hayat, T. "Series solutions for the stagnation flow of a secondgrade fluid over a shrinking sheet", Applied Mathematics and Mechanics, 30(10), p. 1255 (2009).

7. Mehmood, R., Nadeem, S., and Akbar, N.S. "Nonorthogonal stagnation point flow of a micropolar second grade fluid towards a stretching surface with heat transfer", Journal of the Taiwan Institute of Chemical Engineers, 44(4), pp. 586-595 (2013).

8. Akinbobola, T.E. and Okoya, S.S. "The flow of second grade fluid over a stretching sheet with variable thermal conductivity and viscosity in the presence of heat source/sink", Journal of the Nigerian Mathematical Society, 34(3), pp. 331-342 (2015).

9. Majeed, A., Javed, T., and Ghaffari, A. "Numerical investigation on flow of second grade fluid due to stretching cylinder with Soret and Dufour effects", Journal of Molecular Liquids, 221, pp. 878-884 (2016).

10. Khan, M., ur Rahman, M., and Manzur, M. "Axisymmetric flow and heat transfer to modified second grade fluid over a radially stretching sheet", Results in Physics, 7, pp. 878-889 (2017).

11. Ghadikolaei, S.S., Hosseinzadeh, K., Yassari, M., Sadeghi, H., and Ganji, D.D. "Analytical and numerical solution of non-Newtonian second-grade fluid flow on a stretching sheet", Thermal Science and Engineering Progress, 5, pp. 309-316 (2018).

12. Alamri, S.Z., Khan, A.A., Azeez, M., and Ellahi, R. "Effects of mass transfer on MHD second grade fluid towards stretching cylinder: A novel perspective of Cattaneo-Christov heat flux model", Physics Letters A., 383(2-3), pp. 276-281 (2019).

13. Bilal, S., Mustafa, Z., Rehman, K.U., and Malik, M.Y. "MHD second grade nanofluid flow induced by a rotatory cone", Journal of Nanofluids, 8(4), pp. 876884 (2019).

14. Elkoumy, S.R., Barakat, E.I., and Abdelsalam, S.I. "Hall and transverse magnetic field effects on peristaltic flow of a Maxwell fluid through a porous medium", Global J. Pure Appl. Math., 9(2), pp. 187203 (2013).

15. Mekheimer, K.S., Hasona, W.M., El-Shekhipy, A.A., and Zaher, A.Z. "Electrokinetics of dielectric nonNewtonian bio fluids with heat transfer through a flexible channel", Numerical Study. Computational Methods in Science and Technology, 23(4), pp. 331341 (2017).

16. Mekheimer, K.S., Hasona, W.M., Abo-Elkhair, R.E., and Zaher, A.Z. "Peristaltic blood flow with gold nanoparticles as a third grade nanofluid in catheter: Application of cancer therapy", Physics Letters A., 382(2-3), pp. 85-93 (2018).

17. Abdelsalam, S.I., Bhatti, M.M., Zeeshan, A., Riaz, A., and Beg, O.A. "Metachronal propulsion of electricallyconducting viscoelastic particle-fluid suspension in a ciliated channel under transverse magnetic field: mathematical modelling", Physica Scripta, 94, pp. 115301115314 (2019).
18. Eldesoky, I.M., Abdelsalam, S.I., El-Askary, W.A., and Ahmed, M.M. "The integrated thermal effect in conjunction with slip conditions on peristaltically induced particle-fluid transport in a catheterized pipe", Journal of Porous Media, 23(7), pp. 695-713 (2020).

19. Crane, L.J. "Flow past a stretching plate", Zeitschrift für Angewandte Mathematik und Physik ZAMP, 21(4), pp. 645-647 (1970).

20. Mekheimer, K.S., Salem, A.M., and Zaher, A.Z. "Peristaltically induced flow due to a surface acoustic wavy moving wall", Chinese Journal of Physics, 51(5), pp. 968-982 (2013).

21. Mekheimer, K.S., Salem, A.M., and Zaher, A.Z. "Peristatcally induced MHD slip flow in a porous medium due to a surface acoustic wavy wall", Journal of the Egyptian Mathematical Society, 22(1), pp. 143-151 (2014).

22. Malvandi, A., Hedayati, F., and Ganji, D.D. "Nanofluid flow on the stagnation point of a permeable non-linearly stretching/shrinking sheet", Alexandria Engineering Journal, 57(4), pp. 2199-2208 (Dec. 2018).

23. Abdelsalam, S.I. and Mekheimer, K.S. "Couple stress fluid flow in a rotating channel with peristalsis", Journal of Hydrodynamics, 30(2), pp. 307-316 (2018).

24. Abdelsalam, S.I. and Bhatti, M.M. "The study of non-Newtonian nanofluid with hall and ion slip effects on peristaltically induced motion in a non-uniform channel", RSC advances, 8(15), pp. 7904-7915 (2018).

25. Mekheimer, K.S., Zaher, A.Z., and Hasona, W.M. "Entropy of AC electro-kinetics for blood mediated gold or copper nanoparticles as a drug agent for thermotherapy of oncology", Chinese Journal of Physics 65, pp. 123-138 (June 2020).

26. Bhatti, M.M., Marin, M., Zeeshan, A., Ellahi, R., and Abdelsalam, S.I. "Swimming of motile gyrotactic microorganisms and nanoparticles in blood flow through anisotropically tapered arteries", Frontiers in Physics, 8, p. 95 (2020).

27. Khan, M., Salahuddin, T., Tanveer, A., Malik, M.Y., and Hussain, A. "Change in internal energy of thermal diffusion stagnation point Maxwell nanofluid flow along with solar radiation and thermal conductivity", Chinese Journal of Chemical Engineering, 27(10), pp. 2352-2358 (2019).

28. Nadeem, S., Ahmed, Z., and Saleem, S. "Carbon nanotubes effects in magneto nanofluid flow over a curved stretching surface with variable viscosity", $M i$ crosystem Technologies, 25(7), pp. 2881-2888 (2020).

29. Choi, U.S. "Enhancing thermal conductivity of fluids with nanoparticles", Development and Applications of Non-Newtonian Flows Edited by Siginer, DA and Wang, HP, EFD-Vol. 231/MD-Vol. 66. ASME (1995).

30. Mahian, O., Kianifar, A., Kalogirou, S.A., Pop, I., and Wongwises, S.A. "Review of the applications of nanofluids in solar energy", International Journal of Heat and Mass Transfer, 57(2), pp. 582-594 (2013). 
31. Turkyilmazoglu, M. "Nanofluid flow and heat transfer due to a rotating disk", Computers and Fluids, 94, pp. 139-146 (2014).

32. Abbas, N., Saleem, S., Nadeem, S., Alderremy, A.A., and Khan, A.U. "On stagnation point flow of a micro polar nanofluid past a circular cylinder with velocity and thermal slip", Results in Physics, 9, pp. 1224-1232 (2018).

33. Abdelsalam, S.I. and Bhatti, M.M. "The impact of impinging TiO2 nanoparticles in Prandtl nanofluid along with endoscopic and variable magnetic field effects on peristaltic blood flow", Multidiscipline Modeling in Materials and Structures, 14(3), pp. 530-548 (2018).

34. Eldesoky, I., Abdelsalam, S., El-Askary, W., El-Refaey, A., and Ahmed, M. "Joint effect of thermal energy and magnetic field on particulate fluid suspension in a catheterized tube", Bionanoscience, 9(3), pp. 723-739 (2019).

35. Abdelsalam, S.I. and Bhatti, M.M. "New insight into AuNP applications in tumour treatment and cosmetics through wavy annuli at the nanoscale", Scientific Reports, 9(1), pp. 1-14 (2019).

36. Bhatti, M.M., Zeeshan, A., Ellahi, R., Bég, O.A., and Kadir, A. "Effects of coagulation on the two-phase peristaltic pumping of magnetized Prandtl biofluid through an endoscopic annular geometry containing a porous medium", Chinese Journal of Physics, 58, pp. 222-234 (2019)

37. Abd Elmaboud, Y. and Abdelsalam, S.I. "DC/AC magnetohydrodynamic-micropump of a generalized Burger's fluid in an annulus", Physica Scripta, 94(11), p. 115209 (2019).

38. Abd Elmaboud, Y., Abdelsalam, S.I., Mekheimer, K.S., and Vafai, K. "Electromagnetic flow for two-layer immiscible fluids", Engineering Science and Technology, An International Journal, 22(1), pp. 237-248 (2019).

39. Sohail, M., Naz, R., and Abdelsalam, S.I. "Application of non-Fourier double diffusions theories to the boundary-layer flow of a yield stress exhibiting fluid model", Physica A: Statistical Mechanics and its Applications, 537, p. 122753 (2020).

40. Abumandour, R.M., Eldesoky, I.M., Kamel, M.H., Ahmed, M.M., and Abdelsalam, S.I. "Peristaltic thrusting of a thermal-viscosity nanofluid through a resilient vertical pipe", Zeitschrift für Naturforschung, A., 75(8), pp. 727-738 (2020).

41. Momin, G.G. "Experimental investigation of mixed convection with water-Al2O3 and hybrid nanofluid in inclined tube for laminar flow", Int. J. Sci. Technol. Res., 2, pp. 195-202 (2013).

42. Suresh, S., Venkitaraj, K.P., Selvakumar, P., and Chandrasekar, M. "Synthesis of Al2O3-Cu/water hybrid nanofluids using two step method and its thermo physical properties", Colloids and Surfaces A: Physicochemical and Engineering Aspects, 388(1-3), pp. 41-48 (2011).
43. Nadeem, S., Abbas, N., and Khan, AU. "Characteristics of three dimensional stagnation point flow of Hybrid nanofluid past a circular cylinder", Results in Physics, 8, pp. 829-835 (2018).

44. Nadeem, S. and Abbas, N. "On both MHD and slip effect in micropolar hybrid nanofluid past a circular cylinder under stagnation point region", Canadian Journal of Physics, (ja) (2018).

45. Eldesoky, I.M., Abdelsalam, S.I., El-Askary, W.A., and Ahmed, M.M. "Concurrent development of thermal energy with magnetic field on a particle-fluid suspension through a porous conduit", BioNano Science, $\mathbf{9}(1)$, pp. 186-202 (2019).

46. Abdelsalam, S.I. and Bhatti, M.M. "Anomalous reactivity of thermo-bioconvective nanofluid towards oxytactic microorganisms", Applied Mathematics and Mechanics, 41(5), pp. 711-724 (2020).

47. Abdelsalam, S.I. and Sohail, M. "Numerical approach of variable thermophysical features of dissipated viscous nanofluid comprising gyrotactic microorganisms", Pramana, Journal of Physics, 94(1) (2020).

48. Abdelsalam, S.I., Mekheimer, K.S., and Zaher, A.Z. "Alterations in blood stream by electroosmotic forces of hybrid nanofluid through diseased artery: Aneurysmal/stenosed segment", Chinese Journal of Physics, 67, pp. 314-329 (Oct. 2020).

49. Sadaf, H. and Abdelsalam, S.I. "Adverse effects of a hybrid nanofluid in a wavy non-uniform annulus with convective boundary conditions", $R S C$ Advances, $\mathbf{1 0}(26)$.

50. Sohail, M., Naz, R., and Abdelsalam, S.I. "On the onset of entropy generation for a nanofluid with thermal radiation and gyrotactic microorganisms through 3D flows", Physica Scripta, 95(4), 045206 (2020).

51. Ariel, P.D. "On extra boundary condition in the stagnation point flow of a second grade fluid", International Journal of Engineering Science, 40(2), pp. 145$162(2002)$.

52. Wang, C.Y. "Stagnation flow towards a shrinking sheet", International Journal of Non-Linear Mechanics, 43(5), pp. 377-382 (2008).

53. Bachok, N., Ishak, A., and Pop, I. "Stagnation-point flow over a stretching/shrinking sheet in a nanofluid", Nanoscale Research Letters, 6(1), p. 623 (2011).

54. Malvandi, A., Hedayati, F., and Ganji, D.D. "Nanofluid flow on the stagnation point of a permeable non-linearly stretching/shrinking sheet", Alexandria Engineering Journal 57(4), pp. 2199-2208 (2017).

55. Yacob, N.A., Ishak, A., and Pop, I. "Falkner-Skan problem for a static or moving wedge in nanofluids", International Journal of Thermal Sciences, 50(2), pp. 133-139 (2011).

\section{Biographies}

Nadeem Abbas was born on September 15, 1990 in District Jhang, Punjab, Pakistan. He earned his 
MS degree in Mathematics in 2014 from the University of the Punjab Lahore, Pakistan and MPhil and PhD degrees from Quaid-i-Azam University Islamabad, Pakistan. Now, he is working as Assistant Professor in the Department of Mathematics, Riphah International University, Faisalabad Campus, Faisalabad, Pakistan. He has published more than 30 research articles in well reputed international journals, having more than 470 citations.

Sohail Nadeem is working as Professor/Chairman at the Department of Mathematics at Quaid-i-Azam University, Islamabad, Pakistan. More than $25 \mathrm{PhD}$ scholars and more than 100 MPhil students have completed their respective degrees under his supervision. He has published over 500 research papers in reputed international journals, with over 7000 citations. Several national and international awards have been conferred on him. He is also a member of several editorial boards in well reputed international journals. He is a member of various scientific committees in the country.

Anber Saleem is working as Professor at the Department of 3Islamabad Medical and Dental College, Islamabad, Pakistan. She has published more than 50 research articles in well reputed international journals, with over 500 citations. She is also a member of several editorial boards in well reputed international journals. $\mathrm{He}$ is a member of various scientific committees in the country.
Alibek Issakhov is working as Professor in department of Mathematics Al-Farabi Kazakh National University, av. al-Farabi, Almaty, Kazakhstan. He is a member of various scientific committees in the country. He has published more than 25 research articles in well reputed international journals, with over 1000 citations. Several national and international awards have been conferred on him. He is also a member of several editorial boards in well reputed international journals.

M.A. Abdel-Sattar is working as Professor in department of Mathematics, Faculty of Science, King Khalid University, Saudi Arabia. He is a member of various scientific committees in the country. He has published more than 27 research articles in well reputed international journals, with over 105 citations. Several national and international awards have been conferred on him. He is also a member of several editorial boards in well reputed international journals.

Shaban Aly is working as Professor in Department of Mathematics, Al-Azhar University, Assiut, Egypt. $\mathrm{He}$ is a member of various scientific committees in the country. He has published more than 73 research articles in well reputed international journals, with over 883 citations. Several national and international awards have been conferred on him. He is also a member of several editorial boards in well reputed international journals. 